\title{
THE POTENTIONAL OF PLANTS TO CLEANUP METALS FROM AN OLD LANDFILL SITE
}

\author{
Yahya Jani ${ }^{1}$, Researcher $(P h D)$ \\ Charlotte Marchand ${ }^{2}$ \\ William Hogland ${ }^{1}$, Professor (PhD) \\ ${ }^{1}$ Biology \& Environmental Sciences, Linnaeus University, Sweden \\ ${ }^{2}$ Biodiversity Centre of Montreal University, Canada
}

\begin{abstract}
Old landfill sites contain different hazardous materials like heavy metals which have the ability to affects the entire environment. These places are sometimes covered by plants to increase the stability of the soil and to reduce the effects of erosion. 15 soil samples (3 samples from each place) and 5-7 timothy-grass (Phleum pretense) plants from 5 different places were taken from an old landfill place in an active landfill site in Högbytorp /Sweden owned by Ragn-sells Group Company. XRF scanning was used to analyze the metal content of soil samples and of plants. High concentrations of metals were detected in the soil samples like Fe with an average of about 25000 ppm, Mn about 250 ppm and 2800 ppm of Ti. The plants results showed an average concentration of Fe in the shoots about 730 ppm, Mn about 60 ppm and Ti about 1760 ppm. On the other hand, the roots results showed an average concentration of about 10000 ppm of Fe, about 160 ppm of Mn and 2200 ppm of Ti. These results gave the indication that the Timothygrass has the ability to extract metals from contaminated soils and can help to cleanup these soils.
\end{abstract}

\section{KEYWORDS}

Phytoremediation, Heavy metals, Old landfill sites, Soil pollution, Timothy-grass

\section{INTRODUCTION}

Soils are considered to be the potential sink for the discharged heavy metals from all the industrial and human activities to the environment. However, little information is known about the mechanism of bonding these metals to the soil and also the mechanism of releasing these metals from the soil [1]. Metal concentration and bioavailability vary according to the time and environment and depends on the variation of the soil properties like the composition, the reduction/oxidation reaction, adsorption/desorption and on the chemical properties of the received metals [2]. 


\section{Linnaeus ECO-TECH '14 \\ Kalmar, Sweden, November 24-26, 2014}

In one hand, old landfill sites soils represent a potential risk for the human health and for the environment because of the high content of these soils to high concentrations of different heavy metals. These heavy metals have an excellent potential to transfer to the ecological system and the food chain [1,2]. Different methods have been used for the remediation of metals from soils like extraction with chelating agents (EDTA or other biodegradable agents) [3], sequential acid leaching [4], washing [5], hydrometallurgy technique [6], Bioelectrochemistry [7] and phytoremediation [8].

On the other hand, not only environmental and health problems our societies are facing nowadays, but also serious discussions regarding scarcity of important natural resources have been carried out throughout the world. Natural constituents that cause contamination are being depleted in their primary sources, including among them the metals iron, copper, zinc, the rare earth metals and the nutrients [10].

One of the most important remediation techniques is phytoremediation, especially phytoextraction, which is an environmental friendly technique using bioremediation method in which plants are used to uptake metals from contaminated soils [8]. Phytoextraction is a promising technique compared to the other remediation techniques due to the low cost and low energy consumption. However, the success of this technique depends on time, the amount of the plants biomass, the concentration of the metals in soil, the bioavailability of the metals in soil and the ability of the plants to live in the sites weather [9].

Timothy-grass (Phleum pretense) is the most widely grown forage grass in whole Scandinavia [11]. It is also well known in different cold weather countries like the Baltic Sea countries and Canada. Timothy has the ability to produce high good quality yield of forage under long hard winter conditions and because of that it can be a good phytoremediation agent if it can accumulate heavy metals from soils [12].

The present research explores the ability of Timothy-grass plant to extract the metals: iron (Fe), manganese ( $\mathrm{Mn}$ ) and titanium (Ti) from an old landfill site in Högbytorp in Sweden. The Timothy-grass plants have been planted in the site for more than 10 years. These plants have been also used to feed animals during all these years. A Semi-quantified X-ray fluorescence analysis (XRF) was used to analyze the metal content of 15 soil samples (triplicates from 5 different lines) and to analyze the metal content of the shoots and the roots of about 5-7 Timothy-grass plants from the same chosen 5 lines. 
Linnaeus ECO-TECH '14

Kalmar, Sweden, November 24-26, 2014

\section{MATERIAL AND METHODS}

\subsection{Site description}

Högbytorp landfill is Ragn-Sells largest waste treatment facility and is located $40 \mathrm{~km}$ northwest of Stockholm. This landfill receives 700000 tons of waste every year making the landfill one of the largest landfills in Sweden. The landfill works with the treatment and recycling of different wastes like contaminated soil, oily sludge from car washes, organic materials, PTP - paper, wood and plastics, metals scrap, ash, medical waste, hazardous waste disposal, and wastes from municipalities, industries and households. The landfill consists of a complex mixture of organic and inorganic materials. The inorganics include the ashes, paint, glue residue, and asbestos. While, the organic materials consist largely of household, construction and industrial waste, digested sludge and horse manure.

The studied area was an old landfill place which was closed for more than 10 years and covered with plants (mostly Timothy-grass). The site area was about $500 \mathrm{~m}^{2}$ and divided to 5 planted lines and each line about $5 \mathrm{~m}$ in width and about $100 \mathrm{~m}$ in length. The space between each two lines about 20-25 $\mathrm{m}$. The grass from these lines was used to feed animals within the area.

\subsection{Sampling and analysis}

15 soil samples were collected from the 5 different planted lines (three samples from each line) and 5-7 Timothy-grass plants were also collected from each one of these lines. The soil samples were taken from different points inside each line and from different depths, up to $30 \mathrm{~cm}$. The plants were taken out carefully from the soils with their roots. The plants roots were washed carefully three times with tap water and once with deionized water to remove all the soils from them. The soil samples were stored in plastic bags for the analysis while the plants were kept in open plastic containers in ambient temperature for two weeks to be well dried before the analysis.

Semi-quantified X-ray fluorescence analysis (XRF), Olympus DS-4000 (Innov-X system, USA), was used to analyze the soil samples and the dry grinded shoots and roots of the Timothy-grass plants. The scanning was repeated three times for each sample (in three different points) and the average was taken as a final value. Then the average of the three soil triplicates was taken as the result of the metal content for the same line. 


\section{Linnaeus ECO-TECH '14}

Kalmar, Sweden, November 24-26, 2014

\section{RESULTS AND DISCUSSIONS}

As shown in table (1), the metal content of Fe in soil and in Timothy-grass roots was higher compared to that of Ti and Mn. While, the metal content of Ti was higher than that of Fe and Mn in the Timothy-grass shoots.

Östman et al., [13] investigated the metal and organic content of three different places in Högbytorp landfill in 2006. The results showed high concentrations of Fe with an average of (55450 ppm) and Mn with an average of (729.75 ppm). Unfortunately, there was no information about Ti. In the present study the metal content of $\mathrm{Fe}$ and $\mathrm{Mn}$ in soil was low compared to that of Östman [13]. This means that the Timothy-grass reduced the metal content of Fe by about $56 \%$ and of Mn by about $65 \%$. These results give the indication that the Timothy-grass has the ability to uptake these metals from soil, and also $\mathrm{Ti}$, and can be used as a good phytoremediation agent. The present results were in agreement with that of Jing et al. [12] which showed also the ability of Timothy-grass to be a good phytoremediation agent.

Table 1. Metal content of Ti, Mn and Fe (mg/kg dry matter) for the Timothy-grass shoots and roots and the soil in the different studied sampling lines.

\begin{tabular}{|c|c|c|c|c|c|c|c|c|c|}
\hline \multirow[t]{2}{*}{$\begin{array}{l}\text { Sampling } \\
\text { line }\end{array}$} & \multicolumn{3}{|c|}{$\begin{array}{l}\text { Metal content in } \\
\text { Shoots mg/kg }\end{array}$} & \multicolumn{3}{|c|}{$\begin{array}{l}\text { Metal content in Roots } \\
\mathrm{mg} / \mathrm{kg}\end{array}$} & \multicolumn{3}{|c|}{$\begin{array}{l}\text { Metal content in Soil } \\
\mathrm{mg} / \mathrm{kg}\end{array}$} \\
\hline & $\mathrm{Ti}$ & $\mathrm{Mn}$ & $\mathrm{Fe}$ & $\mathrm{Ti}$ & $\mathrm{Mn}$ & $\mathrm{Fe}$ & $\mathrm{Ti}$ & $\mathrm{Mn}$ & $\mathrm{Fe}$ \\
\hline 1 & 4381 & 93 & 1733 & 682 & 147 & 8168 & 1869 & 205 & 22660 \\
\hline 2 & 414 & 57 & 301 & 2747 & 225 & 7977 & 2063 & 240 & 23732 \\
\hline 3 & 899 & 55 & 784 & 3562 & 188 & 17956 & 2191 & 243 & 23970 \\
\hline 4 & 1036 & 47,7 & 457 & 1027 & 179 & 13499 & 2181 & 245 & 24120 \\
\hline 5 & 2073 & 43,7 & 383 & 3312 & 71,7 & 2458 & 2489 & 354 & 26946 \\
\hline Mean & 1760.9 & 59.28 & 731.6 & 2266 & 162.14 & 10011.6 & 2158.6 & 257.4 & 24285.6 \\
\hline 8 & 1584.68 & 19.60 & 589.04 & 1327.52 & 57.69 & 5913.35 & 225.67 & 56.44 & 1593.25 \\
\hline
\end{tabular}

Figures 1, 2 and 3 show the percentage of the metal content of the three studied metals in the different studied sampling lines. The results showed that the Timothy-grass shoots were rich with a high concentration of Ti compared to that of $\mathrm{Fe}$ and $\mathrm{Mn}$ and especially in lines 1 and 5 . This means that the Timothy-grass shoots showed a high selectivity to extract and save Ti. While, the Timothy-grass roots showed a different behavior by saving a High concentration of Fe and with a highest concentration in lines 1, 3 and 4.

The Mn contents were low compared to that of Fe and Ti but the Timothy-grass showed also the ability to uptake this metal in both the shoots and the roots as shown in figures 1 and 2. But, the Mn content was higher in the roots as shown in table (1). 


\section{Linnaeus ECO-TECH '14}

Kalmar, Sweden, November 24-26, 2014

The soil results, as shown in figure 3, showed a higher content of Fe (24285 ppm) compared to that of $\mathrm{Ti}$ and $\mathrm{Mn}$ and for all the 5 studied sampling lines. This means that using phytoremediation technique alone for such high content of metals is not efficient because of the need for long periods of time to remediate such sites [8,9].

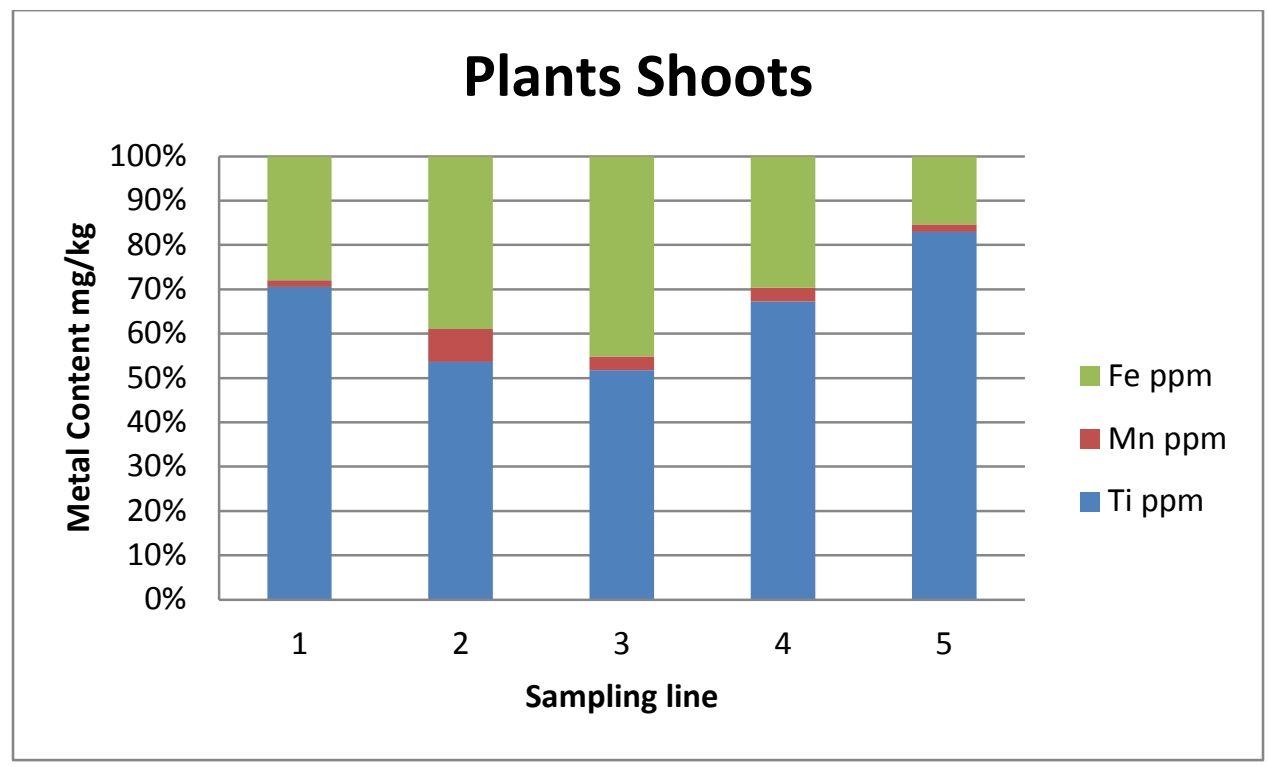

Figure 1. The percentage of the metal content of $\mathrm{Ti}, \mathrm{Mn}$ and Fe in each sampling line in the Timothy-grass shoots.

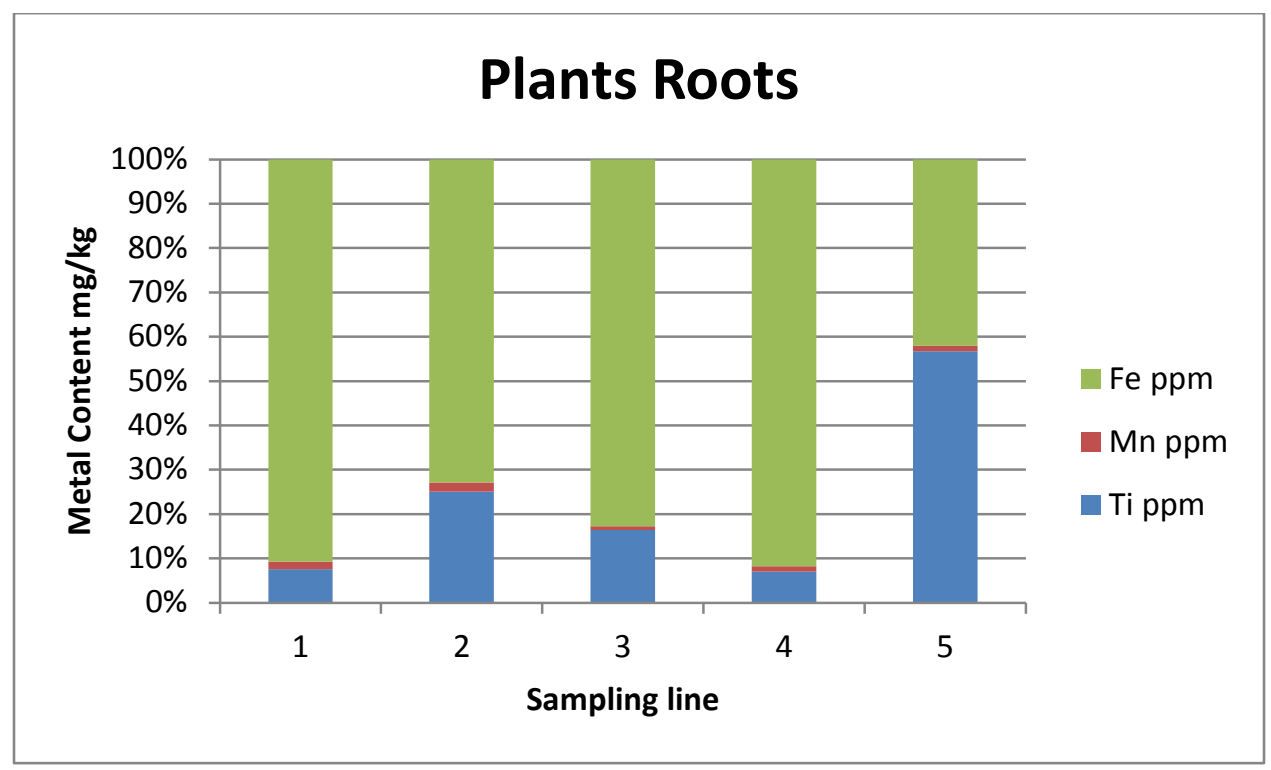


Figure 2. The percentage of the metal content of $\mathrm{Ti}, \mathrm{Mn}$ and Fe in each sampling line in the Timothy-grass roots.

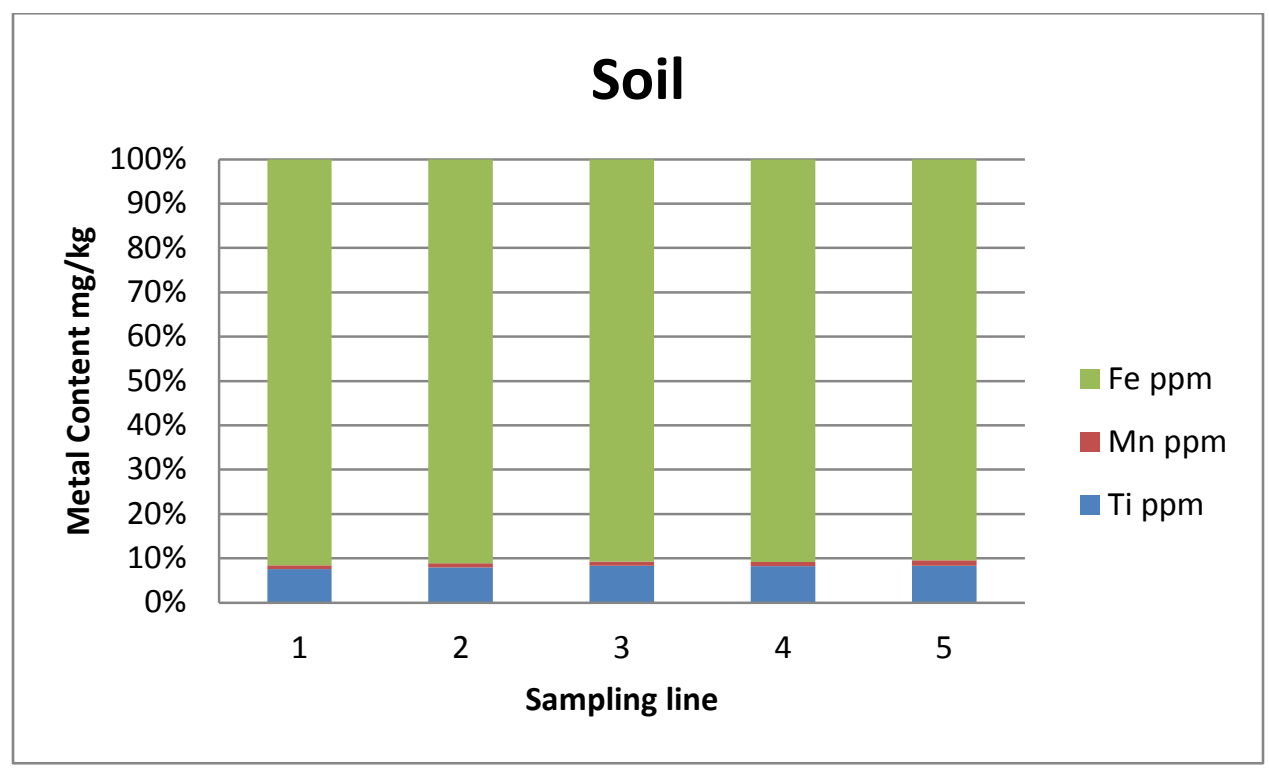

Figure 3. The percentage of the metal content of $\mathrm{Ti}, \mathrm{Mn}$ and Fe in each sampling line in the soil.

\section{CONCLUSIONS}

The results of the present study showed that Timothy-grass can be used as a phytoremediation agent to extract heavy metals from soils. The Timothy-grass showed the ability to uptake Ti from soil and save it inside its shoots. While, the roots showed a selectivity to extract and save Fe and Mn from the soil.

However, the results confirmed that phytoremediation is not a realistic method for high content of metals concentration in soil. Using phytoremediation can reduce the metal content but the time needed will be so long and there will be always a high risk for the spreading of these heavy metals to the surface and the ground water. But, phytoremediation can be a good choice as a second method after the use of another remediation method. 
Linnaeus ECO-TECH '14

Kalmar, Sweden, November 24-26, 2014

\section{ACKNOWLEDGEMENTS}

Special thanks are detected to the Swedish Institute gave financial support to the project "Closing the Life Cycle of Landfills - Landfill Mining in the Baltic Sea Region for future" and Ragn-sells Group Company for the technical/practical help to carry out this study.

\section{References}

[1] S. Masi, D. Caniani, E. Grieco, D.S. Lioi, I.M. Mancini, (2014). Assessment of the possible reuse of MSW coming from landfill mining of old open dumpsites. Waste Management 34:702710.

[2] M. Barbieri, G. Sappa, S. Vitale, B. Parisse, M. Battistel, (2014). Soil control of trace metals concentrations in landfills: A case study of the largest landfill in Europe, Malagrotta, Rome. Journal of Geochemical Exploration 143:146-154.

[3] P. Hu, B. Yang, C. Dong, L. Chen, X. Cao, J. Zhao, L. Wu, Y. Luo, P. Christie, (2014). Assessment of EDTA heap leaching of an agricultural soil highly contaminated with heavy meals. Chemosphere 117: 532-537.

[4] Federal Remediation Technologies Roundtable (FRTR), (2007). Remediation technologies screening matrix and reference guides, version 4.0.

[5] Mann, M.J., (1999). Full-scale and pilot-scale soil washing. J. Hazard Mater 66:119-136.

[6] Y. Xiao, Y. Yang, J. Berg, J. Sietsma, H. Agterhuis, G Visser, D. Bol, (2013). Hydrometallurgical recovery of copper from complex mixtures of end-of-life shredded ICT products. Hydrometallurgy 140: 128-134.

[7] J. Varia, S. Martínez, S. V. Orta, S. Bull, S. Roy, (2013). Bioelectrochemical metal remediation and recovery of $\mathrm{Au3}+, \mathrm{Co} 2+$ and Fe3+ metal ions. Electrochimica Acta 95 :125131.

[8] Z. Li, L. Wu, P. Hu, Y. Luo, H. Zhang, P. Christie, (2014). Repeated phytoextraction of metal-contaminated soils using the cadmium/zinc hyperaccumulator Sedum plumbizincicola. Environmental Pollution 189: 176-183.

[9] Saifullah, E. Meers, M. Qadir, P. de Caritat, F.M.G. Tack, G. Du Laing, M.H. Zia, (2009). EDTA-assisted Pb phytoextraction. Chemosphere 74: 1279-1291.

[10] N. Gilbert, (2009). The disappearing nutrient. Nature, 46:716-718. 


\section{Linnaeus ECO-TECH'14 \\ Kalmar, Sweden, November 24-26, 2014}

[11] M. Höglind, H. Hanslin, M. van Oijen, (2005). Timothy regrowth, tillering and leaf area dynamics following spring harvest at two growth stages. Field Crops Research 93:51-63.

[12] Q. Jing, G. Bélanger, V. Baron, H. Bonesmo, P. Virkajärvi, D. Young, (2012). Regrowth simulation of the perennial grass timothy. Ecological Modelling 232: 64-77.

[13] M. Östman, O. Wahlberg, S. Ågren, A. Mårtensson, (2006). Metal and organic matter contents in a combined household and industrial landfill. Waste Management 26:29-40. 